\title{
Virtual reality in theatre education and design practice - new developments and applications
}

Iryna Kuksa University of Warwick

\begin{abstract}
The global use of Information and Communication Technologies (ICTs) has already established new approaches to theatre education and research, shifting traditional methods of knowledge delivery towards a more visually enhanced experience, which is especially important for teaching scenography. In this paper, I examine the role of multimedia within the field of theatre studies, with particular focus on the theory and practice of theatre design and education. I discuss various IT applications that have transformed the way we experience, learn and co-create our cultural heritage. I explore a suite of rapidly developing communication and computer-visualization techniques that enable reciprocal exchange between students, theatre performances and artefacts. Eventually, I analyse novel technology-mediated teaching techniques that attempt to provide a new media platform for visually enhanced information transfer. My findings indicate that the recent developments in the personalization of knowledge delivery, and also in student-centred study and e-learning, necessitate the transformation of the learners from passive consumers of digital products to active and creative participants in the learning experience.
\end{abstract}

\section{Key words}

theatre design

educational software

digital scenery

virtual reality

\section{Introduction}

In his 1964 book Understanding Media: the Extensions of Man Marshall McLuhan said: 'Under electric technology the entire business of man becomes learning and knowing' (McLuhan 1964: 69). Indeed, computer technologies offer vast amounts of information that require users to develop specific skills to sort, analyse and synthesize digital resources. Theatre and performance studies are no exception. Modern technologies of computation 
greatly influence the development of new media theatre, specifically contributing to its design and implementation phases. They also have a profound impact on theoretical and practical educational aspects of the performance studies classroom. Often in theatre education the subject of study is delivered only verbally, without an external visual element of learning. Colin Beardon and Terry Enright (1999) argue that the fact that students experience theatre mainly vocally and televisually prevents them from picturing the spatial properties of live theatre and stage design. New media technologies provide opportunities to promote the visual side of the course material and offer instantly a more improvisatory approach to the process of knowledge visualization. They assist students in their self-directed learning and encourage active participation and collaboration with study sources, rather than passivity in their consumption.

In this paper, I argue that technology-based teaching techniques can benefit the whole process of learning, not only through experimenting with existing course designs but also by transforming the established methods of knowledge delivery. I investigate the impact of cyberspace and digital technologies on contemporary education, outline some important models of learning and analyse a paradigm shift in the role of the teacher in the theatre studies classroom. I explore the advantages and disadvantages of relatively new mediacommunication platforms such as the Internet, 3D simulations and avatar technologies, and assess their impact on knowledge transfer with particular focus on the field of theatre studies. Furthermore, I argue that computer-mediated learning should be carefully balanced between the consumption of information and an active, and also creative, engagement with available media. To support my argument, I provide a critical overview of existing computer-based projects and evaluate recent tendencies in the use of computer technologies for creative and educational purposes. I attempt, firstly, to explain the major reasons for employing new technologies and, secondly, to investigate their relationship with conventional teaching and learning techniques. Finally, I introduce a novel software evaluation framework, which I designed specifically for assessing the overall effectiveness of new media in the theatre studies classroom.

\section{Learning and teaching in the digital age - background and new strategies}

In recent years, the process of education has changed noticeably. For example, there has been a shift towards an emphasis on teaching and training as an extended process. Jim Smith and Andrea Spurling observe that a new culture of lifelong learning is emerging, where 
'individuals are constantly seeking to learn, and exhibit both individual commitment to learn for personal reasons, but also a social commitment towards mutual learning in the wider social context' (Smith and Spurling 2001: 114). Indeed, learning as a whole is a constantly evolving social process. It includes both 'an individual and a social element, the latter always reflecting current societal conditions, so that the learning result has the character of an individual phenomenon which is always socially and societally marked' (Illeris 2003: 227). Nowadays, the role of the teacher is no longer that of an instructor but that of an interpreter of course resources, with a greater emphasis on the students and their active engagement with learning materials. This evolution from the passive consumption of information to active engagement with it has enabled learners to control their own study process (Forsyth 1998; Jonassen and Land 2000; Laurillard 2002). Technological innovations play an important role here. They increase the demand for reforms in the educational sector and, as a result, strengthen the linkage between the teachers' ability to make appropriate use of technology and the students' academic achievements (Valdez et al. 2000).

Recent technological advances heightened the need for more interactive, enjoyable and customizable learning. Information and Communication Technologies (ICTs) offer numerous opportunities for monitoring the process of study and, consequently, increase motivation and improve students' attitudes towards course material, as well as their interest in gaining new knowledge. At present, new media act as an inseparable part of the teacher-student interaction and cooperative information exchange, becoming a necessity, for example, for e-learning. ICTs also generally integrate with constructivism's emphasis on individual learning in a socio-cultural setting (Selwyn et al. 2005), which promotes personalized construction of meaning and the active role of the learner in the interpretation of reality (Larochelle and Bednarz 1998: 5). Technology-based learning not only amplifies, extends and enhances learners' cognition (Jonassen and Reeves 1996), but also facilitates access to resources and helps students to store, reshape and analyse relevant data. Furthermore, technology provides a rich space for learners to collect quality information from various areas of knowledge, and also to discover and understand conceptual relationships between learning resources that were previously segmented and utilized in isolated contexts (Valdez et al. 2000). Applications such as hypertext and hypermedia enable interactivity of study content, which promotes a personalized approach for each individual student. For instance, semantic networking (i.e. hypertextual flow of data) engages learners in a complete re-organization of their knowledge through the explicit interrelationship of study concepts. It also gives an opportunity for creating, manipulating and sharing authentic data which leads 
towards the creation of larger and more accurate sets of information stored in cyberspace or specialized devices. Modern computer applications are not only able to provide almost instant feedback and multiple access to the course material from any networked computer, but also enable various types of virtual simulations prior to the real-world experience. This kind of interactivity, however, requires that both the learner and the notional teacher actively use the facilities and options provided, which is not always the case. Obviously, if there is no interaction there is also no communication. New media technologies not only encourage students to take responsibility for their own learning, but also advance teachers' productivity. For example, computer-mediated communication (CMC) networks offer modern teachers a unique opportunity of accessing a professional community, where their expertise and experience can be shared with fellow colleagues, and where they can participate in professional discourse about improving practice (Corcoran 1995).

Although the interest in new media technologies as an educational medium is increasing, it should be noted that, despite considerable advantages, there are also some weaknesses, even in one of the most popular means of knowledge transfer - the Internet. One of the biggest problems that presently exists, and that requires immediate attention, is the deficiency of Internet standards (e.g. data formats and protection, communications protocols), which undermines the very concept of e-learning. Undoubtedly, cyberspace, mainly due to its 'liquid' nature, demands a continual update of information, because without it the whole concept of interactive cyber-education is rendered meaningless. There is little doubt that as yet no technology fulfils all existing educational demands. However, a significant advantage of computer-based education is that, if used appropriately, technology supports and promotes exploration, independent enquiry and collaborative integration of information. As a result, it enables group thinking, problem solving and task orientation.

\section{Dimensions of the learning process}

It has been already established that learning is an open, complex and explorative process. Therefore, in order to understand fully the aforementioned developments, it is necessary to examine the different ways in which we consume new knowledge. There are several commonly recognized dimensions of the study process. In this paper, I focus particularly on perceptions and attitudes that affect the students' ability to learn, as well as on the integration and extension of their knowledge.

Benjamin Bloom's (1956) taxonomy is generally accepted as a system for classifying learning objectives and goals. He used a number of learning verbs (for the full schema, see 
Bloom 1956) to classify the levels of intellectual behaviour necessary for the process of knowledge delivery. Bloom argued that the use of these verbs is crucial for defining the desired outcomes of a course or a study module. Indeed, clear articulation of learning outcomes is necessary for students to develop their progress files, but, in order to be successful, the process of learning should be carefully assessed. Thus, by introducing his Structure of the Observed Learning Outcome (SOLO) taxonomy, John Biggs distinguished five stages of a learner's perception of a subject (see Biggs and Collis 1982; Biggs 1999) that are essential for assessing the quality of the learning outcomes - both quantitative and qualitative. There is also a need to encourage students to rigorously analyse information they have gained, making it part of their long-term memory. As a result, the most effective learners develop the ability for critical analysis, creative thinking and, consequently, are able to adjust their learning preferences.

We all learn in different ways. In 2001, Nils Enlund specified four important types of learning, which are particularly relevant to e-learning. The first type is performance learning or, to be more precise, learning in situations such as in a conventional classroom, during a lecture or presentation, where the learner is a relatively passive observer and receiver of information. Collaborative learning is the second type, which encourages studying in teams of peers in structured and goal-oriented activities, such as project groups in problem-based learning. The next mode of knowledge consumption is individual study, where the delivery of information occurs through solitary activity, cognitive or physical, as in reading, writing, solving problems, experimenting, practising and reflecting (also see Marton et al. 1993). Finally, the last type of learning consists of social interaction, which stimulates learning in serendipitous, unstructured social situations, where a spontaneous exchange of ideas, information or experiences takes place, for example, during a chance meeting at the coffee machine or at the newsstand. The importance of the students' social environments has also been emphasized by Knud Illeris (2003), who noted that dimensions of learning are all deeply embedded in a societal context - especially the social dimension of communication and cooperation.

Regardless of the learning type, or the taxonomy used to characterize it, students must become reflective learners (see Kolb 1984) in order to develop transferable skills. This emphasis on reflection and task-based learning may have resulted from the rapid development of new media technologies throughout the 1980s and 1990s. At first, this interest in new, powerful methods of delivering information brought back the 'instructional' approach to teaching, which is mainly determined by policy-makers. With further 
development of e-learning techniques, however, teachers focused on new tendencies in reflective learning (e-portfolios), social learning (e-moderation) and online discussions (see Laudrillard 2002; Salmon 2004). Nevertheless, some researchers still argue that, on closer examination, these emerging collaborative pedagogical e-techniques might be building on linear teaching experiences (Gulati 2004). This prompts the question of how computer technologies can be incorporated naturally into various models of knowledge delivery and learning environments. Clearly, the various dimensions of learning have relevance for understanding, and enhancing, the process of teaching. The delivery of knowledge should be well-structured and study materials need to be approached in a consistent and systematic manner. In this regard, ICTs offer various benefits for the further interpretation of a study subject, and for teacher-student interaction (in cases where students and teachers are becoming equal partners). Firstly, the structured nature of computer-based materials gives learners a professional view of the content and the possibility to test and re-test their knowledge. Secondly, the ability to work on the course subject at a time convenient to the learner improves motivation and promotes positive attitudes towards the educational process.

In order to intensify the cross-fertilization and exchange of study material, it is necessary for computer-based learning to be interdisciplinary (Denard 2004). Additionally, there is a greater need for computer-generated educational applications to be diverse in their format, providing various interactions and learning options. In e-learning, for example, the onscreen information should be presented in an understandable and predictable manner. This can be quite challenging to achieve, due to the continuously changing nature of Virtual Learning Environments (VLEs). To address this problem, several researchers (e.g. Guynup and Carlson 2000; André and Rist 2002) have suggested using personalized virtual characters, so-called 'avatars', as communication channels and content-delivery platforms. An avatar is a pedagogical agent or, in other words, a personalized online representation of an e-learning application, which generally simulates human activity, personalizes the dialogue with the user and links the user with the information they need to perform a given task (Sheth 2003). Natalie K. Person and Arthur C. Graesser (2006) define avatars within elearning environments as peers, competitors, co-learners, but also as either helpers or instructors, who should be able to give explanations and hints to a learner, monitor the process of learning and provide instant feedback. Raj Sheth further argues that 'avatars are becoming more important where interactivity, learner engagement, and cultural factors are important design considerations' (Sheth 2003: 2). Indeed, avatars are able to learn the users' preferences and interests, make suggestions, function with minimal supervision and 
customize their assistance according to each participant. One might also argue that they represent the next major wave in online communication and education techniques, dramatically enhancing the intuitiveness of navigation. Some of the autonomous agent technologies have already been employed as educational applications, without, however, being adopted for mass-market production. I share Sheth's (2003) belief that the main cause of such poor usage is the failure of the e-learning interface designers to familiarize themselves with the benefits that avatars can offer to the whole computer-based knowledge delivery process. There is no doubt that the lack of interest in such innovative technology affects the acceptance of avatars as a learning tool, also meaning that, to date, a balance between technologies, which could potentially be used for developing educational software and to enhance the technological awareness of designers, teachers and also students, has not yet been established.

\section{Computer-based projects in theatre education and practice: a critical overview}

In teaching theatre history, new technologies serve as an appropriate medium for a visuallyenhanced communication of past theatrical events and artefacts. VLEs can provide a great variety of scholarly materials, but also encourage their interactive exploration, by involving the students directly in the learning process. Such learning environments can engage their users, both imaginatively and intellectually, in a wide range of choices, options and alternative ways of confronting and manipulating historical data. This kind of interaction extends beyond the scope of longer established ways of learning. I suggest that the employment of innovative visualization techniques, such as virtual imaging or 3D simulations of numerous theatrical artefacts, combined with hypertext and other rich media resources, enhances learners' experiences and improves knowledge delivery. On the other hand, such digital reconstructions have to be supported by a vast array of explanatory information in order to be assembled contextually. The integration of virtual reality (VR) modelling into the educational process dramatically increases the efficiency of learning by giving the learners an opportunity to interpret intellectually various destroyed or 'lost' theatre artefacts and places, in a way that was not previously feasible (Fig. 1).

The possibility of employing virtual environments for teaching purposes in theatre studies not only reveals new dimensions in the visual perception of knowledge, but also offers potential for innovative experiments with novel techniques such as immersive VR and telepresence. 


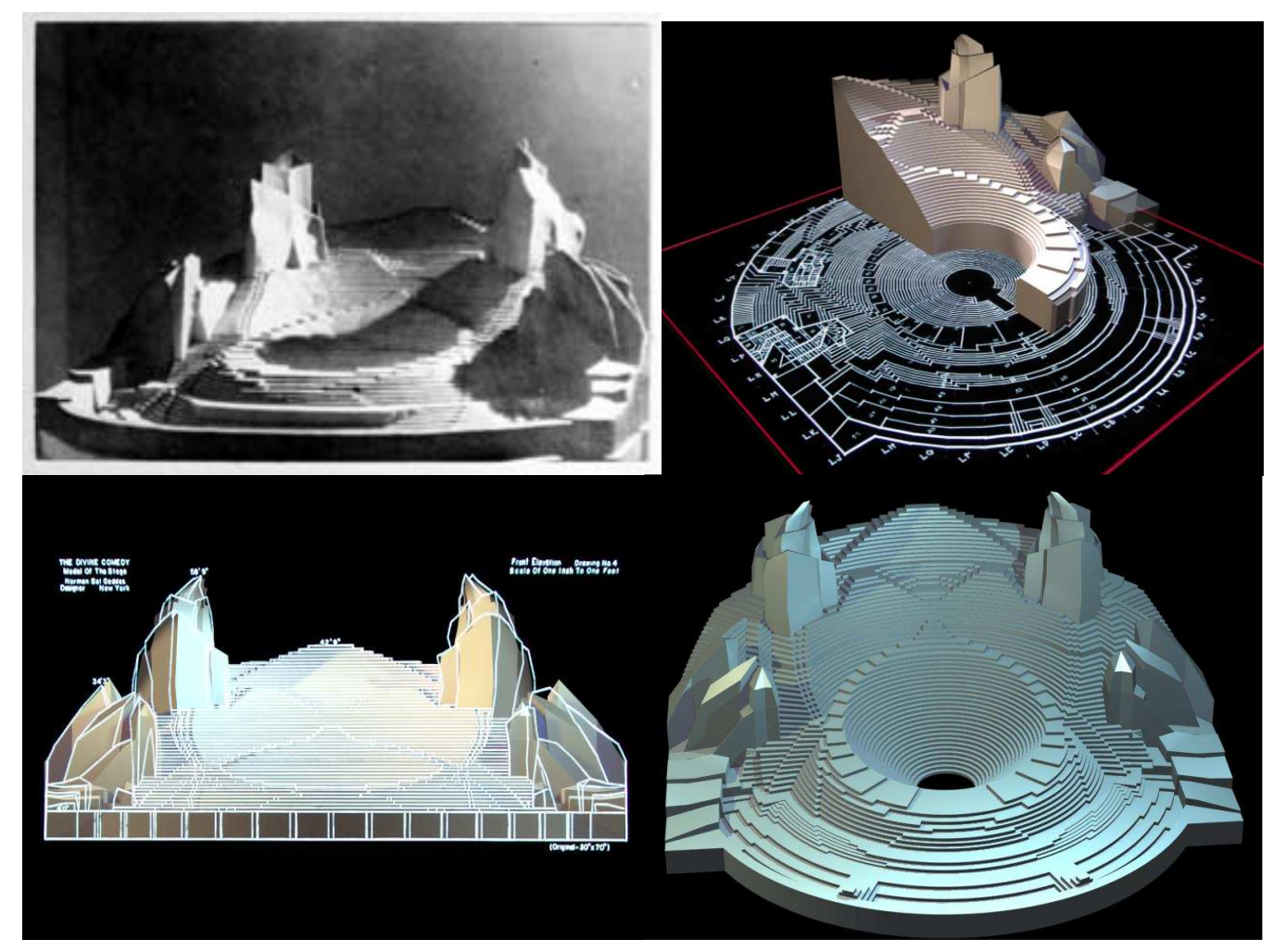

FIGURE 1: The Set-SPECTRUM Project. 3D Reconstruction of Norman Bel Geddes Set Design (1921) for Dante's The Divine Comedy. Authors: Iryna Kuksa and Eugeniya Kareva (see Kuksa, 2007)

While sophisticated applications are still prohibitively expensive, some common software packages (e.g. 3D Studio Max and ArchiCAD) already allow learners to create, view, navigate and explore interactively virtual models of historical theatre sites and stages.

It has already been mentioned in this paper that in recent years ICTs have become a significant part of educational process in the developed world (especially within the school environment). Software technology has also been playing an important role in learning practices. There are three common genres of software packages: enabling software (specialist word processors, Internet browsers and art packages), entertainment software (games and media products) and, finally, educational software, which is linked to a curriculum and/or designed specifically to develop particular skills of the learner (Read 2005). In the field of theatre studies, there is a range of software- and online-based projects that offer a unique opportunity to experience new forms of theatre, entertainment and culture through an amalgamation of virtual reality, installation and performance. Some of them aim to provide new user-friendly ways of accessing media databases of our cultural heritage and build upon 
traditional research and teaching methods. Others employ VR techniques to expand the definition of traditional performance space, sometimes suggesting certain ways and contexts to replace the embodied sites with virtual ones, in order to introduce learners to the spatial and mechanical aspects of theatrical space. These projects aim to evoke new associations, meanings and values that could fundamentally reshape the conventional construction of theatrical and art venues. Such endeavours tend to reflect critically on the relationship between digital technologies and the design of contemporary software interfaces, often in order to achieve better theoretical and practical outcomes and to promote independent and user-centred learning. Furthermore, some of the existing projects tend to bring together into productive liaison different models of study (as in the field of theatre history) while also suggesting a wide range of innovative applications to related subject areas. The questions that need to be asked, however, are whether these projects are effective in terms of educational and professional development and what kind of limitations affect such an approach to knowledge delivery and creativity training?

Since the 1990s, one of the main purposes of ICT-based information space has been the exploration of how new forms of art, performance, entertainment and overall culture can be experienced within mixed-reality spatial environments where participants can interact with computer-generated artefacts in an integrated way. A number of VR-based projects investigate various inhabited digital spaces and are involved in experiments on mixed reality and the understanding of social interactions. They concentrate on the integration of artistic, technical and social perspectives, which can result in highly engaging multi-user interfaces, which would serve to provide innovative forms of communication between the participants. In addition, these projects emphasize research on the new boundaries between real and virtual spaces. The THEATRON project (Fig. 2), for instance, was amongst the first examples of how VR technologies could be employed as a teaching means in theatre education. It emerged as a specific computer-generated tool that made it possible to discover, investigate and analyse visual dimensions of theatre history. The abbreviation THEATRON decodes as 'Theatre History in Europe: Architectural and Textual Resources Online'. The project was conceived by Professor Richard Beacham of the School of Theatre Studies at the University of Warwick, and Dr Peter Eversmann of the Department of Theatre Studies at the University of Amsterdam in 1998. The idea behind the THEATRON online module was not only interesting and innovative, but also quite challenging for established teaching techniques in theatre education. The project aimed to enable its users to experience 'virtually' the evolution of the European theatre and provided a well-grounded understanding of the elements of 
architectural space and also time in 3D. A range of historic navigable models of theatre buildings, ranging from the antique to the nineteenth century, was developed, enabling students to examine particular theatrical spaces and to assess what impact they might have had on contemporary performances and audiences.

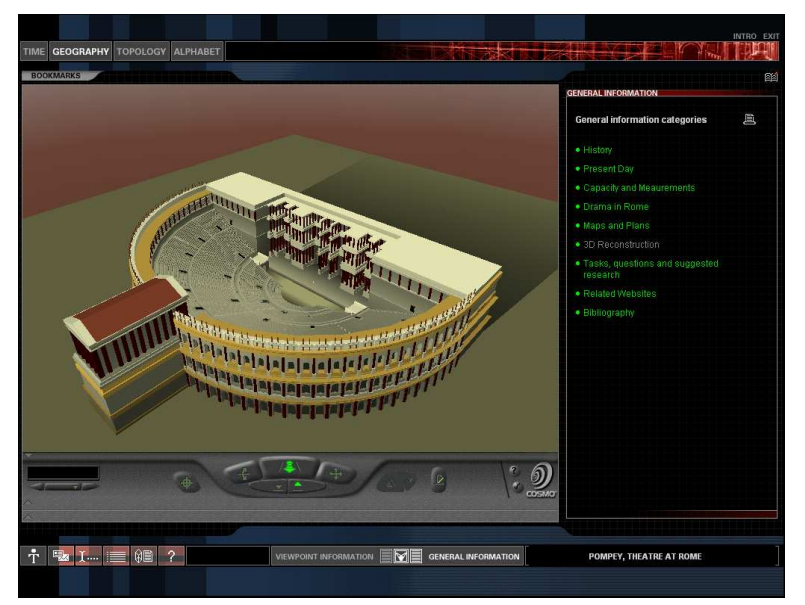

FIGURE 2: The THEATRON online module. Source: King's Visualization Lab.

Recently, the THEATRON team (now based in King's College London) started collaboration with a consortium of UK universities and higher education organizations in order to produce a set of complex virtual spaces in the virtual world - Second Life (SL). During the last few years, SL has become a popular educational domain for numerous HE institutions that pioneered a number of projects in order to provide their users with innovative, interactive teaching and learning resources. THEATRON aims not only to incorporate already existing materials within this virtual environment but also, according to its creators, to supplement the 3D models with 'a spectrum of original interactive tools, scenarios and automated tutorials, incorporating manipulable and customisable actors, props, sound effects, lighting and scenic technologies, streaming video and scripts enabling individual and group movement/choreography' (The Higher Education Academy English Subject Centre, 2006)

The 'Electronic Arenas for Culture, Art, Performance and Entertainment' (eRENA) project, which is run by academic institutions in Germany, Sweden, Switzerland and England, as well as major corporate partners and a commercial Small and Medium Enterprise (SME), is also a good example here. It aims to bridge the gap between contemporary small-scale, real-time communication technologies, such as video conferencing, and current massivescale non-participative broadcast techniques. In perspective, the project intends to publicly demonstrate and evaluate the results of its findings through thematic spaces, initially based 
on the extension of the traditional cultural forms of galleries, performances and television. This is relevant here, because such types of interactive performances attempt to problematize the boundary between the 'existing' and the 'imaginary', and bring the participants to a new understanding of how two realities are blurred. The project proposed to locate its users in a collaborative virtual environment, where 'real' reality integrates into 'virtual' and vice versa. The main goal of this potential performative experience is to explain how mass media can distort the appraisal of the world beyond one's personal perceptions, by providing a setting for individual and social interactions in VR and theatrical spaces (eRENA report, Shaw 2000). This project presents interactive performance as a game, an installation or an electronic 'arena' with a technical infrastructure that consists of such technologies as distributed VR and projection environments, a user interface, audio monitoring, feedback and a card-activated video replay.

The Desert Rain project is another example of participatory experience that pushes VR technology beyond its supposed limits. It is a result of collaboration between the Blast Theory group and the Mixed Reality Lab, University of Nottingham, and is an example of significant work in the area of performance art and new media:

The piece is influenced by Jean Baudrillard's assertion that the Gulf War did not take place because it was in fact a virtual event. Whilst remaining deeply suspicious of this kind of theoretical position Blast Theory recognize that this idea touches upon a crucial shift in our perception and understanding of the world around us. It asserts that the role of the media, advertising and of the entertainment industries in the presentation of events is casually misleading at best and perniciously deceptive at worst. ... While these ideas form the backdrop to Desert Rain the piece is not intended to be a demonstration of this theory merely to accept its significance in informing our view of the relationship of the real to the virtual and especially in its assertion that the virtual has a daily presence in our lives.

(Desert Rain, Conceptual Background Available:

http://www.blasttheory.co.uk/bt/work desertrain.html)

The participants in this project are placed in a collaborative VR environment with virtual scenery projected onto rain curtains (Fig. 3) for the purpose of exploring a number of landscapes and experiencing various types of media including live audio and video links to other players. The main outcome of the Desert Rain installation can be described as a new 
form of storytelling between interacting audience members that, in a productive way, challenges traditional ideas of narrative by confusing conventional understandings of who is a performer and who is a viewer (Shaw 2000).

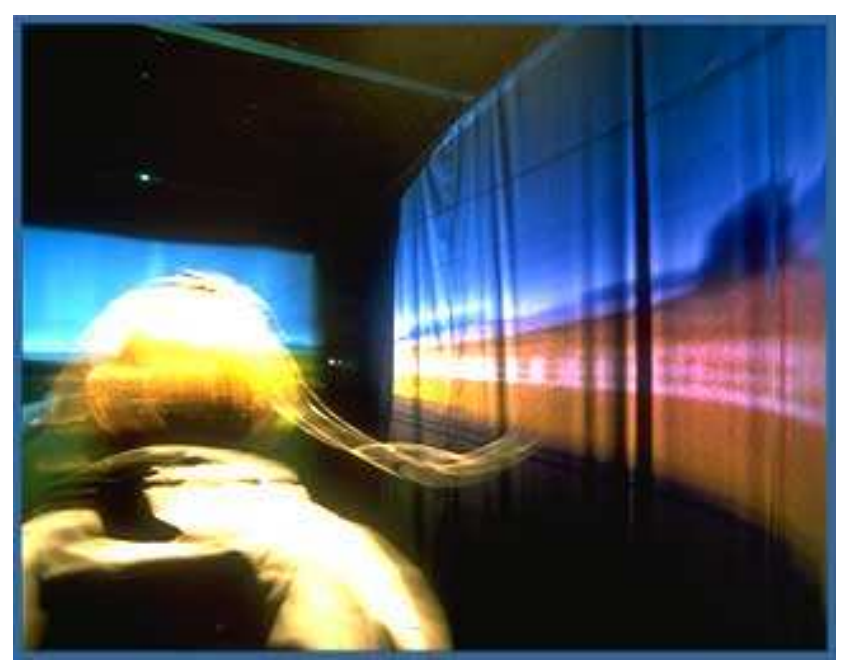

FIGURE 3: Desert Rain Installation. Source: http://www.erena.kth.se/desert.html.

A number of computer-based projects aim to develop a prototype of a generic platform for interactive performances and storytelling within mixed-reality worlds (e.g. works of The Institute for the Exploration of Virtual Realities, University of Kansas). While analysing these kinds of applications, it is particularly important to concentrate on the notion of their flexibility to be installed in different environments, such as e-learning spaces, museums, information points and situational training facilities. Nevertheless, to fulfil users' entertainment and educational demands fully, all technical specifications of these platforms (e.g. interactivity, animation of virtual characters, rendering applications containing graphics and sounds, device management, gesture recognition for tracking hand movements and 3D scanning) must be carefully designed and integrated within the appropriate learning environment. The audience research (i.e. the intended users' needs and aspirations) should also be undertaken together with a pilot testing of any technology-mediated project for revealing possible technological and motivational failures. It should be mentioned that educational software is a relatively new area of research, requiring a lot of attention to the issues of usable educational interfaces, designing learning activities (see Laurillard 2002; Sim et al. 2004) and developing better feedback options (see Gadanidis 2004). Therefore, a strong evaluation framework is needed to assess existing e-learning products and develop new ones. 


\section{Evaluating educational software}

At present, there is a wide range of educational software available for teaching and learning purposes in various fields of knowledge, including theatre studies. These packages, however, are not of equal quality and may only partially fulfil the educational needs of students, without satisfying all of them. It is very important to distinguish what is appropriate for a particular study module, meaning that each piece of educational software should be designed to deliver a particular learning experience. Most software packages do not neatly fall into just one category, but could be easily classified under several. Unfortunately, drama and performance studies are still relatively unexplored territories, in terms of the use of computer programs specifically designed for teaching purposes. Therefore, there is a need for theatre educators to become more knowledgeable about the various types of available educational packages and their significant features, in order to make full use of them in the classroom, and possibly to design their own.

Theatre education has always balanced between the demands of theory and practice. Traditionally, the visualization of the evolution of performance space, its scenery, costumes and, certainly, specific aspects of its technological development, was complicated. Educational software products for teaching theoretical and practical elements of theatre can strongly influence the overall quality of the study process and learning outcomes. The existing software packages (e.g. A Shakespeare Suite project, Open Stages, Visual Assistant, the Cambridge King Lear CD-ROM project) serve numerous course objectives and can be characterized as computer programs for supporting e-learning applications and for designing theatrical spaces and sets in 3D (Fig. 4). It should be noted that Figure 4 represents only two aspects of computer-based theatre education (e-learning and 3D modelling), which are the most important for the present paper. There are, obviously, many other applications that stretch the boundaries of the established theatre classroom, such as the use of motion-capture technology, to create VR performances, or the use of telepresence techniques, which provide a personalized approach to long-distance learning. There are, obviously, many other applications that stretch the boundaries of the established theatre classroom, such as the use of motion-capture technology, to create VR performances, or the use of telepresence techniques, which provide a personalized approach to long-distance learning. 


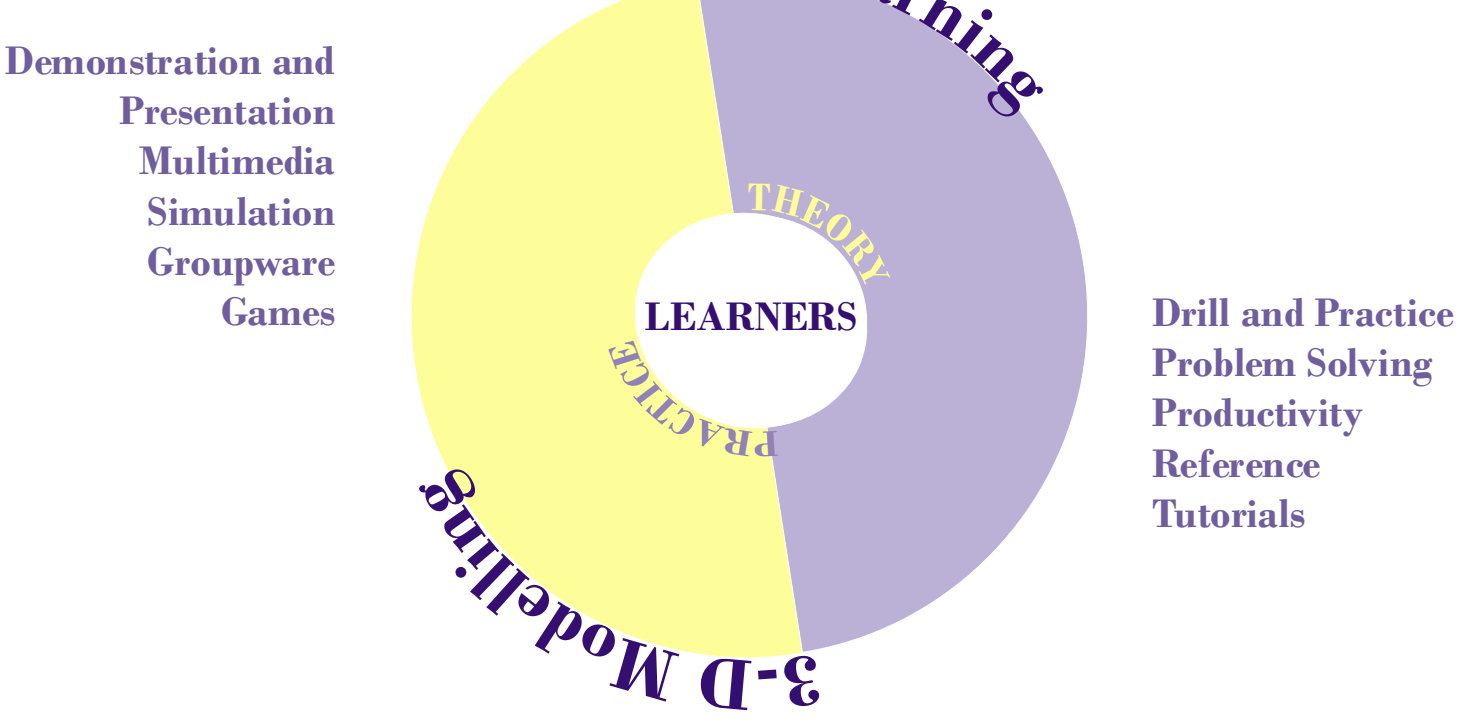

FIGURE 4: Characteristics of Computer-Based Learning in Theatre Studies. Author: Iryna Kuksa.

I have found that in theatre studies most educational software is limited to two types. The first one exists in the format of a database and contains mostly reference materials, such as historical facts, photographs, videos and even technologically sophisticated navigable 3D models of theatre sites (e.g. the THEATRON project). The second type gives its users a unique opportunity to be creative and design, for example, theatrical scenery, lighting or costumes (e.g. the Visual Assistant project). These computer programs do not usually include any supporting or explanatory information on the historical features of various set designs, which therefore makes them purely technical and lacking in an educational aspect. Unfortunately, neither of these types of software packages, despite their innate usefulness, are widely used.

In order to analyse the existing software packages for theatre education and practice, there is a need to create a manageable set of evaluation criteria, which in turn can elicit the users' requirements. Obviously, there are many issues here to consider, for example: evidence of software effectiveness; alignment with HE institutions or individual learners' standards; suitability for users' needs and learning styles; and certainly the total cost of purchasing, maintaining and upgrading the necessary hardware and software. Here, I distinguish and particularly focus on such evaluation criteria of computer-based projects as the learners' profile and learning environment, program content, technical aspects and documentation. These criteria are necessary, in order to familiarize the intended users of the 
educational software packages with their unique and common characteristics, as well as to provide students with their preferable learning style. They are also essential for outlining in what context the learning activity is to occur (e.g. its time frame, format, content and instructional goals). Furthermore, such aspects as the accuracy, currency and balanced presentation of information, logical progression of topics, variety of activities with options for increasing complexity and stereotype-free content are also very important, in order that educational software packages succeed. Other significant facets to be considered before implementation of the computer-based learning product may include the description of specific hardware requirements for operating the application, supplementary materials on the enrichment of learning activities integrated into the curriculum and a teacher's guide, describing the target audience and containing suggestions for classroom use, lesson plans, related exercises and a summary of the content. Finally, various technical and presentational attributes of any study software also play an important role in the process of interactive computer-based learning. Intuitive navigation, rapid retrieval of information and screen transitions, as well as record-keeping features, serve to benefit and monitor the project users' progress.

Certainly, there are several issues to be considered before engaging in the development of a new digital means for theatre-making and education, for example, the danger of social exclusion while interacting with the digital product and frustration caused by the project's underdevelopment (both technological and conceptual). Many of these problems, however, could be avoided if essential research and necessary evaluations and testing of the digital products are undertaken. There is no doubt that the overall effectiveness of any computer program depends on the way information is presented. If the content develops in a logical way, it will stimulate the users' imaginations and curiosities, and provide necessary opportunities for creative problem solving and the accomplishment of the course objectives. The majority of educational software, however, still requires further development work. Thus, one of the purposes of the current paper is to provide an evaluation framework (Table 1) for computer-based educational projects, which would help to assess their efficiency for intended users.

TABLE 1: Software Evaluation. Author: Iryna Kuksa 


\begin{tabular}{|l|l|l|l|}
\hline Criteria & & Project Objectives & Evaluation \\
\hline Learners' Profile & $\begin{array}{l}\text { Characteristics: } \\
\text { Learning Style: }\end{array}$ & & \\
\hline Learning Environment & $\begin{array}{l}\text { Format: } \\
\text { Instructional Goals: }\end{array}$ & & \\
\hline Program Content & $\begin{array}{l}\text { Accuracy: } \\
\text { Currency: } \\
\text { Activity: }\end{array}$ & & \\
\hline Technical Aspects & $\begin{array}{l}\text { Presentation: } \\
\text { Navigation: } \\
\text { Quality: }\end{array}$ & & \\
\hline Documentation & $\begin{array}{l}\text { Guides: } \\
\text { Materials: }\end{array}$ & & \\
\hline Effectiveness: & & & \\
\hline
\end{tabular}

\section{Concluding remarks}

My analyses demonstrate that new media technologies have a double-sided impact on the world of theatre education and design, with two absolutely different outcomes. First of all, the innovative technological devices serve to enhance the established ways of how we learn about the theatre and stage design. On the other hand, they also attempt to change the very nature of scholarship and theatrical performance. This is hardly surprising, because, at present, the development of technological devices is so rapid that they get modified, simplified, miniaturized on an almost daily basis and become routinely integrated into our everyday lives. The evidence from this paper suggests that one of the main concerns that presently exist in theatre studies is the issue of how convenient, presentable and accessible new media are for educational institutions and also creative practitioners. Indeed, the integration of such delivery methods as the world wide web and the Intranet has enabled a more advanced level of personalization, making the customizable interfaces more flexible and suitable for individual demands, and creating a strong link between various types of institutions (e.g. universities, libraries, archives and commercial firms). The DigiCULT Technology Watch Report 2, released in 2004, states that the advantage of interconnections between information units, and of searching across institutional resources, provided by computer technologies is that it helps in dissolving the lines that separate different cultural heritage, educational and commercial organizations. There is little doubt that such an approach to content-sharing helps in establishing new kinds of communities and possibilities to communicate within them; on the other hand, however, these new spaces could promote 
the potential risk of learners' isolation and a detraction from the social aspect of cultural experience.

The main objective of using computer technologies in theatrical space is to investigate new ways of designing, staging and effective teaching. I am convinced that it is crucial to develop visual skills in theatre students, enabling them to use imagery as a creative tool, but also as a means to analyse theatrical performances and artefacts. New media give the visualization process an improvisatory quality and, furthermore, could re-educate our existing perceptions of actual theatre space, and even ourselves as technology users. Traditionally, like visitors to cultural sites, members of theatre audiences and students have been regarded as passive recipients of information, rather than active participants in its interpretation and utilization. Nowadays, the situation is gradually moving towards the personalization of knowledge delivery and also self-oriented, lifelong and e-learning. The accessibility and flexibility of new media technologies support multiple learning styles and give the learners a unique opportunity to configure the form, language and level of the information necessary to complete a course. It should be kept in mind, however, that the introduction and implementation of new learning methods (and consequently devices) should be supported by the development of a content that addresses present educational needs and satisfies a diversity of learners. One might argue that, without the collaborative approaches to study, there is a possibility that students with low motivation may get confused about activities and deadlines, and feel isolated from the teacher and their course-mates. Indeed, at present, the majority of online courses and e-modules are missing the social aspect of the learning process. It seems possible, however, to overcome this social exclusion, by providing a template structure for the course information through the creation of digital databases, or the simple selection of specific online or digital resources for students to use independently and within in-class seminars.

Unfortunately, if used inappropriately, technology can have a negative impact on learning outcomes and even function as a copy-and-paste plagiarism device that significantly lowers the overall quality of a study process. In order to avoid this, there is a need to match technological applications with the intended learning goals, have critical access to hardware that is appropriate to the study expectations and also ensure that the software design and instructional methods surrounding its use are congruent (Valdez et al. 2000). There is little doubt that the process of learning is a complex phenomenon, which should be handled with care. Therefore, I suggest that at the present stage of technological development a blended learning approach (i.e. an amalgamation of online or computer-based and face-to-face 
elements of knowledge delivery) has great potential to become widespread in the theatre studies classroom. First of all, it incorporates a mix of formats, media and activities with more efficient learning outcomes and, secondly, it gradually moves learners from 'traditional' classrooms to e-learning, making new changes easier to accept.

\section{Bibliography:}

- Andre', E. and Rist, T. (2002), 'From Adaptive Hypertext to Personalized Web Companions', Communications of the ACM, 45/5.

- Beardon, C. and Enright, T. (1999), 'The Visual Assistant: Designing Software to Support Creativity', CADE'99 Conference Proceedings, University of Teesside, pp. 5-14.

- Biggs, J. (1999), Teaching for Quality Learning at University, Buckingham: SRHE and Open University Press.

- Biggs, J. and Collis, K. (1982), Evaluating the Quality of Learning: the SOLO taxonomy, New York: Academic Press.

- Bloom, B. S. (ed.) (1956), Taxonomy of Educational Objectives, the Classification of Educational Goals, Handbook I: Cognitive Domain, New York: McKay.

- Corcoran, T. C. (1995), Transforming Professional Development for Teachers. A Guide for State Policymakers, Washington DC: National Governors' Association.

- Denard, H. (2004), 'Performing the Past: the Virtual Revolution in Performance History', in K. Schlesinger (ed.), Performing Arts Resources: Proceedings of the Theatre Library Association Symposium 'Performance Documentation and Preservation in an Online Environment', New York Public Library for the Performing Arts, Lincoln Centre, pp. 54 -70 .

- Enlund, N. (2001), 'Being Virtually There - Reality and Presence in Mediated Learning', Proceedings of the 2001 International Conference on Telecommunications for Education and Training, Charles University, Prague, pp. 55-60.

- Forsyth, I. (1998), Teaching and Learning Materials and the Internet, London: Kogan Page.

- Gadanidis, J. M. (2004), 'Designing Learning Objects for Language Arts Pre-Service Teacher Education in Support of Project-Based Learning Environments', in Proceedings of Society for Information Technology and Teacher Education International Conference, Albuquerque, pp. 3892-99. 
- Gulati, S. (2004), 'Constructivism and Emerging Online Learning Pedagogy: A Discussion for Formal to Acknowledge and Promote the Informal', paper presented at the annual conference of the Universities Association for Continuing Education - Regional Futures: Formal and Informal Learning Perspectives, Centre for Lifelong Learning, University of Glamorgan, 5-7 April.

- Guynup, S. and Carlson, K. (2000), 'Avatar as Content Delivery Platform', Future Generation Computer Systems, 17:1, pp. 65-71.

- Illeris, K. (2003), Three Dimensions of Learning: Contemporary Learning Theory in the Tension Field Between the Cognitive, the Emotional and the Social, Malabar, Florida: Krieger.

- Jonassen, D. H. and Land, S. M. (eds) (2000), Theoretical Foundations of Learning Environments, Mahwah, NJ: Lawrence Erlbaum Associates.

- Jonassen, D. H. and Reeves, T. C. (1996), Learning with Technology: Using Computers as Cognitive Tools, in D. H. Jonassen (ed.), Handbook of Research for Educational Communications and Technology, New York: Simon \& Schuster Macmillan, pp. 693-719.

- Kolb, D. A. (1984), Experiential Learning: Experience as the Source of Learning and Development, Englewood Cliffs, NJ: Prentice-Hall.

- Kuksa, I. (2007), Scenography and New Media Technologies: History, Educational Applications and Visualization Techniques, Ph.D. Thesis: University of Warwick.

- Larochelle, M. and Bednarz N. (1998), 'Constructivism and Education Beyond Epistemological Correctness', in M. Larochelle, N. Bednarz, and J. Garrison, J. (eds), Constructivism and Education, Cambridge: Cambridge University Press, pp. 3-20.

- Laurillard, D. (2002), Rethinking University Teaching: A Conversational Framework for the Effective Use of Teaching Technologies ( $2^{\text {nd }}$ ed.), London and New York: Routledge Falmer.

- Marton F., Dall'Alba G. and Beaty, E. (1993), 'Conceptions of Learning', International Journal of Educational Research, 9:3, pp. 277-99.

- McLuhan, M. (1964), Understanding Media: the Extensions of Man, London: Ark Paperbacks.

- Person, N. K. and Graesser, A. C. (2006), 'Pedagogical Agents and Tutors', in J. W. Guthrie (ed.), Encyclopedia of Education, Macmillan, New York, pp. 1169-72.

- Read, J. C. (2005), 'The ABC of CCl', Interfaces, 6:2, pp. 8-9. 
- Salmon, G. (2004), E-moderating: The Key to Teaching and Learning Online (2 ${ }^{\text {nd }}$ ed.), New York: Routledge Falmer.

- Selwyn, N., Gorard, S. and Furlong, G. J. (2005), Adult Learning in the Digital Age: Information Technology and the Learning Society, London: Routledge.

- Shaw, J. (ed.) (2000), 'Staged Mixed Reality Performance "Desert Rain" by Blast Theory', eRENA D7b.3. Report http://www.nada.kth.se/erena/pdf/D7b3K.pdf. Accessed 7 December 2007.

- Sheth, R. (2003), 'Avatar Technology: Giving a Face to the e-Learning Interface', The eLearning Developers' Journal, 25 August, http://www.elearningguild. com/pdf/2/082503DES-H.pdf. Accessed 7 December 2007.

- Sim, G., Horton, M. and Strong, S. (2004), 'Interfaces for Online Assessment: Friend or Foe?', in Proceedings of the 7th HCl, Educators Workshop, pp. 36-40.

- Smith J. and Spurling, A. (2001), Understanding Motivation for Lifelong Learning, London: Campaign for Learning.

- Valdez, G., McNabb, M., Foertsch, M., Anderson, M., Hawkes, M. and Raack, L. (2000), 'Computer-Based Technology and Learning: Evolving Uses and Expectations', North Central Regional Educational Laboratory, http://www.ncrel.org/tplan/cbtl/toc.htm. Accessed 7 December 2007.

\section{Websites:}

http://www.blasttheory.co.uk/bt/work desertrain.html http://www.erena.kth.se/desert.html http://www.theatron.co.uk/ The Higher Education Academy English Subject Centre: http://www.english.heacademy.ac.uk/explore/projects/archive/technology/tech23.php

\section{Contributor details}

Dr Iryna Kuksa is a scholar interested in practice-based research. The focus of her academic work lies in the dialogue between design, education and new media technologies. She explores the role of multimedia within the field of theatre studies and cultural heritage research, investigating how novel methodologies, including 3D reconstruction of historical artefacts, can be applied to pedagogical practices. Iryna is especially interested in examining various IT applications that transform the way we experience, learn and co-create our cultural 
heritage. Her creative practice includes the development of the Set-SPECTRUM project, which aims to strengthen the established approach to research and teaching, and also to transform the passive consumers of yet another digital product into active participants. Iryna received her BA and MA Industrial Design from the Belarussian State Academy of Arts, and Ph.D. Theatre Studies from the University of Warwick, United Kingdom. Her other university experience includes the University of Oxford and LSE, United Kingdom. For three years she taught MA International Design and Communication Management at the Centre for Cultural Policy Studies at Warwick. 